Supplementary Information for

\title{
Stark Spectroscopic Evidence that a Spin Change Accompanies Light Absorption in Transition Metal Polypyridyl Complexes
}

Andrew B. Maurer and Gerald J. Meyer*

Author affiliation:

Department of Chemistry, University of North Carolina at Chapel Hill, Chapel Hill, North Carolina 27599, United States

Corresponding author:

Gerald J. Meyer (gjmeyer@email.unc.edu)

This file includes:

Supplementary text

Figures S1-S9

Table S1-S5 


\section{Experimental Details}

Materials. Butyronitrile $\left(\mathrm{CH}_{3}\left(\mathrm{CH}_{2}\right)_{2} \mathrm{CN}\right.$, Alfa Aesar, 99\%) was used as received. Indium Tin Oxide coated glass slides (Corning alkaline earth boro-aluminosilicate glass, Indium Tin Oxide coated one surface, $R_{S}=70-100$ ohms, Delta Technologies) were used as received. $\left[\mathrm{Ru}(\mathrm{bpy})_{3}\right]\left(\mathrm{PF}_{6}\right)_{2},\left[\mathrm{Fe}(\mathrm{bpy})_{3}\right]\left(\mathrm{PF}_{6}\right)_{2}$, and $\left[\mathrm{Os}(\mathrm{bpy})_{3}\right]\left(\mathrm{PF}_{6}\right)_{2}$ were synthesized according to previous procedures. ${ }^{1,2}$

Stark Spectrometer. Stark spectroscopy was performed using an apparatus detailed in previous work. ${ }^{3}$ A butyronitrile solution in a thin path length cell comprised of two Indium Tin Oxide coated glass slides was submerged into a liquid nitrogen cooled cryostat and aligned at an angle of $45^{\circ}$ relative to the optical path. An oscillating electric potential generated an oscillating electric field across the sample.

The electroabsorption spectra were collected with a lock-in amplifier. In addition, a reference spectra of the unperturbed system was collected to normalize the data. This reference spectra was then used to convert the collected data to an extinction coefficient spectrum rather than raw intensity through eq S1.

$$
\Delta \varepsilon=\frac{2 \sqrt{2} \Delta I(\vec{F})}{2.303 c l I_{\text {avg }}}
$$

The absorption spectra at 77K were also collected using the same optical arrangement. The tabulated data were collected with a beam chopper.

Data analysis. The Liptay formalism was used to analyze the stark spectra. ${ }^{4,5}$

$$
\Delta \varepsilon(\bar{v})=(f \vec{F})^{2}\left\{A_{\chi} \varepsilon(\bar{v})+\frac{B_{\chi} d}{15 h c d \bar{v}}(\varepsilon(\bar{v}))+\frac{C_{\chi} d^{2}}{30 h^{2} c^{2} d \bar{v}^{2}}(\varepsilon(\bar{v}))\right\}
$$

Where $F$ is the magnitude of the applied electric field, $f$ is a correction for the local field experienced by the molecule, $h$ is Planck's constant, $c$ is the speed of light, and $\epsilon(\bar{v})$ is the molecular extinction coefficient spectrum. For an isotropically oriented immobilized sample, $A_{\chi}$ is negligibly small. The $B_{\chi}$ term is related to the difference in polarizability, $\Delta \vec{\alpha}$, and the $C_{\chi}$ term contains information about the change in dipole moment, $\Delta \vec{\mu}$.

A satisfactory fit was obtained by partitioning the spectrum into multiple bands as outlined by Kober et al., ${ }^{6}$ then obtaining $A \chi, B \chi$, and $C_{\chi}$ for each transition individually. Simulated Stark spectra were calculated from Eq. $\mathrm{S} 1$ for $A^{i}, B^{i}, C^{i}, i=1-n$ where $n$ is the number of transitions assigned to the absorption spectra.

DFT Calculations. Ground-state geometries of all three complexes were optimized with the B3LYP functional using a fixed mixed basis set couple LANL2DZ (for the metal centers) and 6-311G(d,p) (for all other atoms). Solvation effects were considered by using the C-PCM solvent model $\left(\mathrm{CH}_{3} \mathrm{CN}, \varepsilon=37.64\right)$. Values from a population analysis 
of the relevant molecular orbitals is included in Table S5. Calculations were carried using the Gaussian 09 Package. ${ }^{7}$
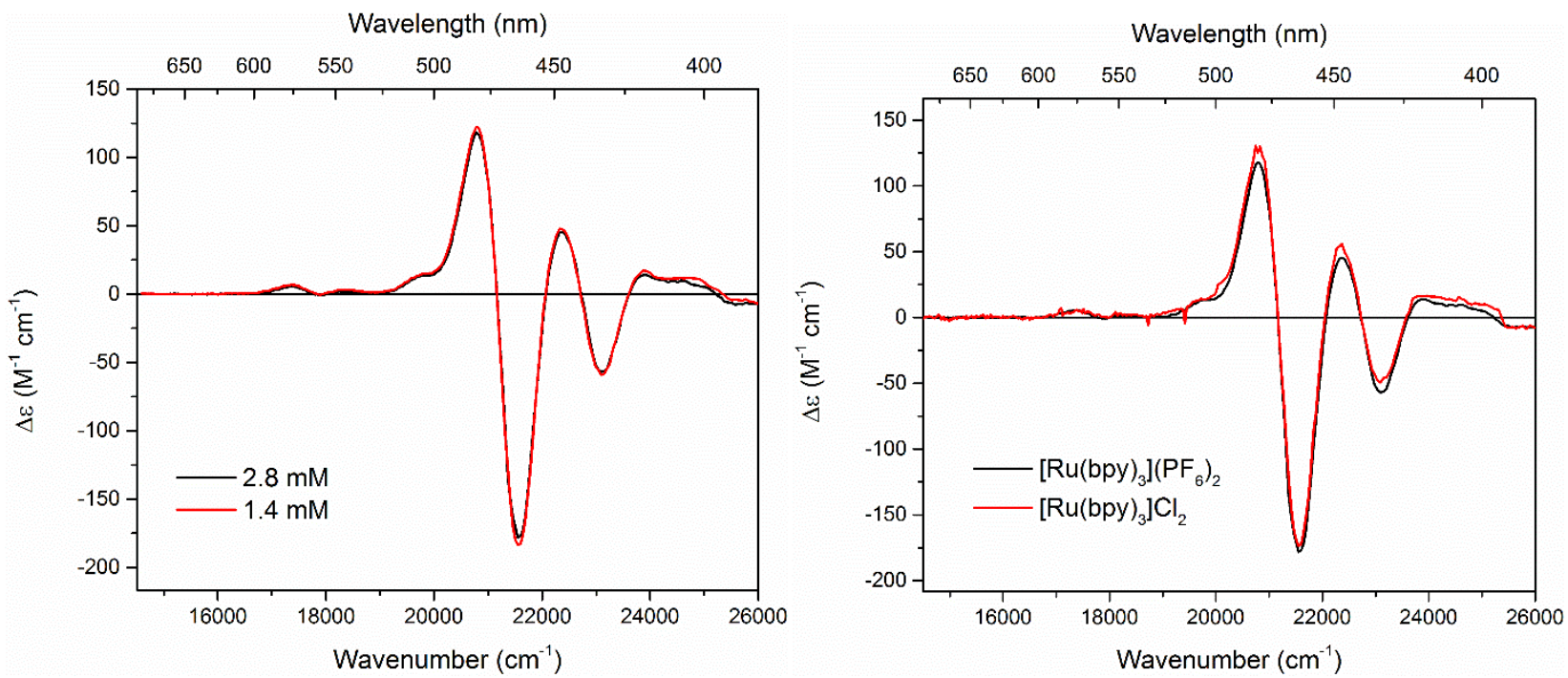

Figure S1. Stark spectra of $\left[\mathrm{Ru}(\mathrm{bpy})_{3}\right]^{2+}$ recorded (Left) at different concentrations and (Right) using $\mathrm{PF}_{6}{ }^{-}$and $\mathrm{Cl}^{-}$ anions. All data is scaled to an applied Field of $1 \mathrm{MV} / \mathrm{cm}$.
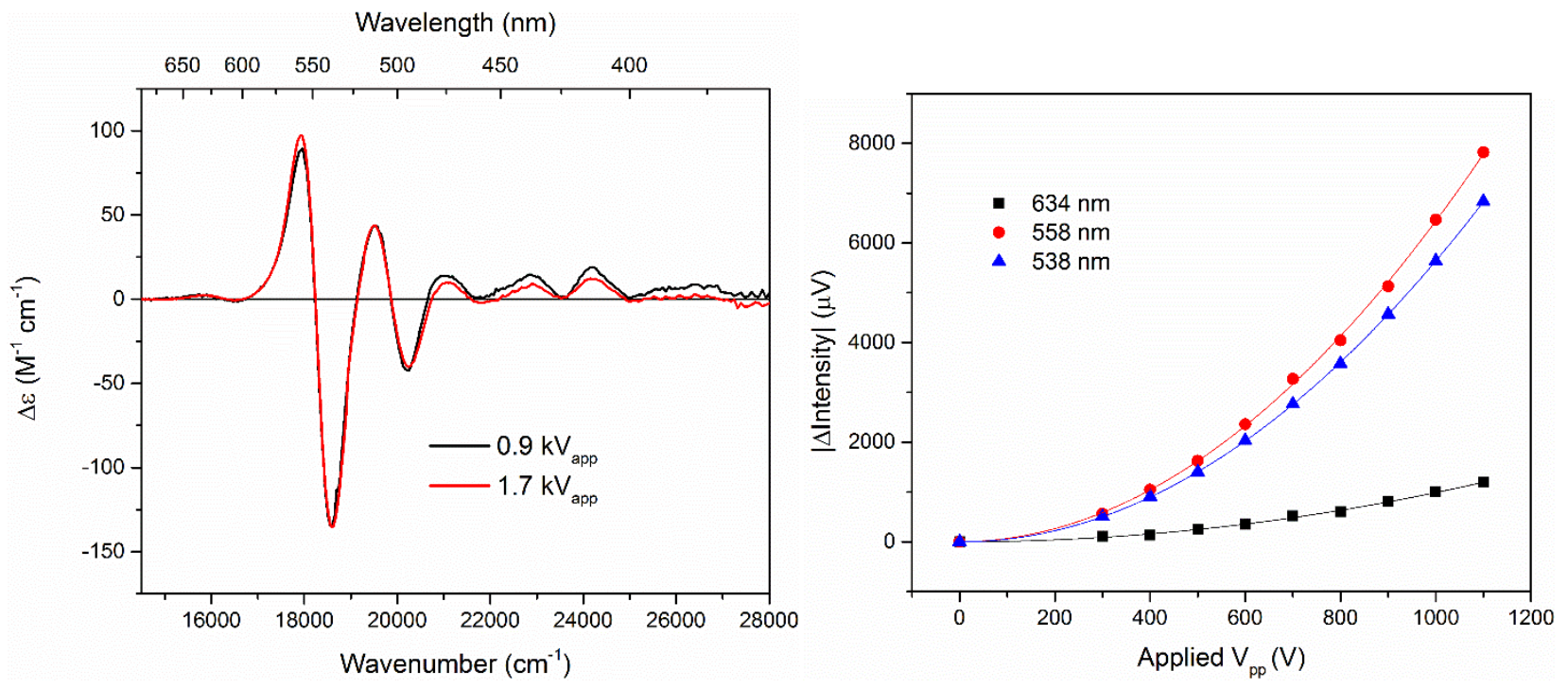

Figure S2. Electroabsorption measurements of $\left[\mathrm{Fe}(\mathrm{bpy})_{3}\right]^{2+}$ at the indicated applied field strengths. (Left) Full Stark spectra scaled to an applied Field of $1 \mathrm{MV} / \mathrm{cm}$. (Right) The absolute value of the intensity of the electroabsorption feature measure at the indicated wavelength as a function of the field strength. Overlaid are quadratic fits. 

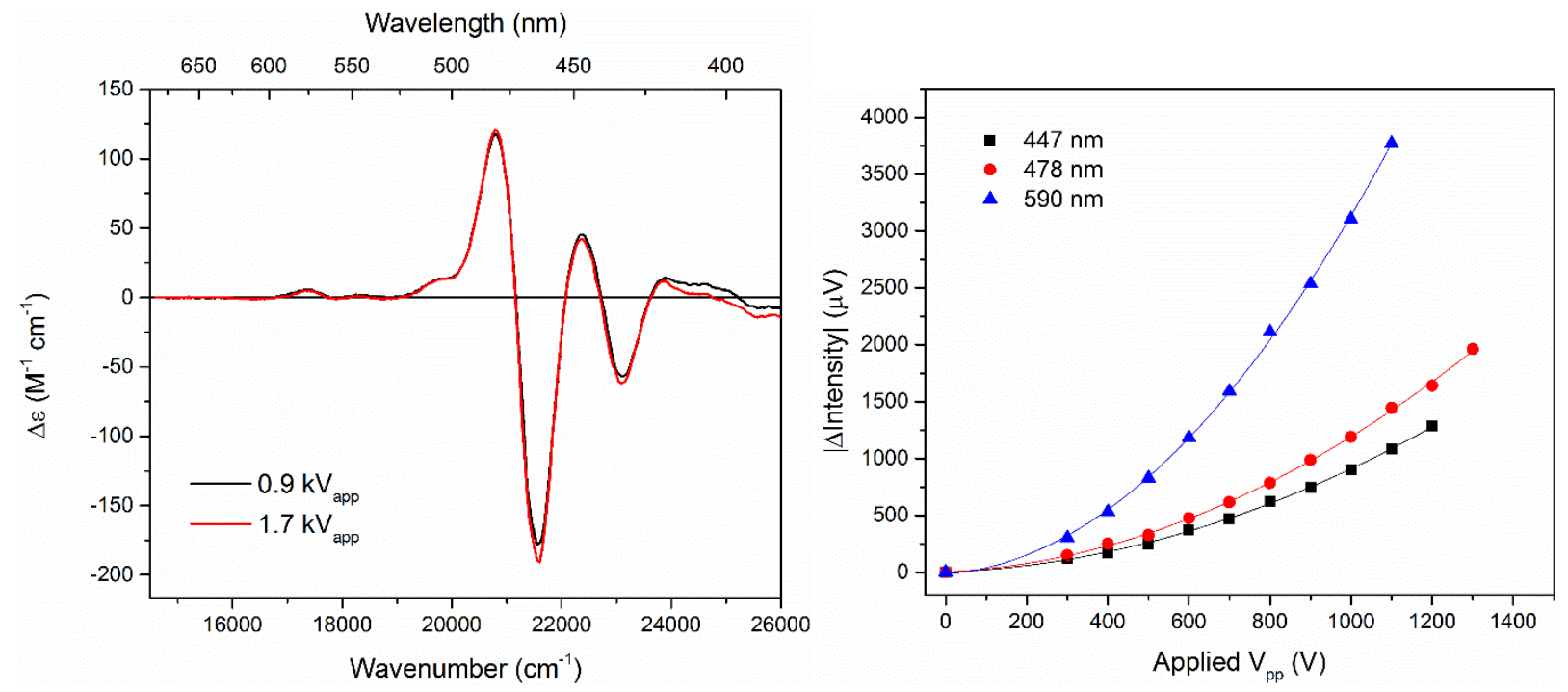

Figure S3. Electroabsorption measurements of $\left[\mathrm{Ru}(\mathrm{bpy})_{3}\right]^{2+}$ at the indicated applied field strengths. (Left) Full Stark spectra scaled to an applied Field of $1 \mathrm{MV} / \mathrm{cm}$. (Right) The absolute value of the intensity of the electroabsorption feature measure at the indicated wavelength as a function of the field strength. Overlaid are quadratic fits. Wavelength $(\mathrm{nm})$
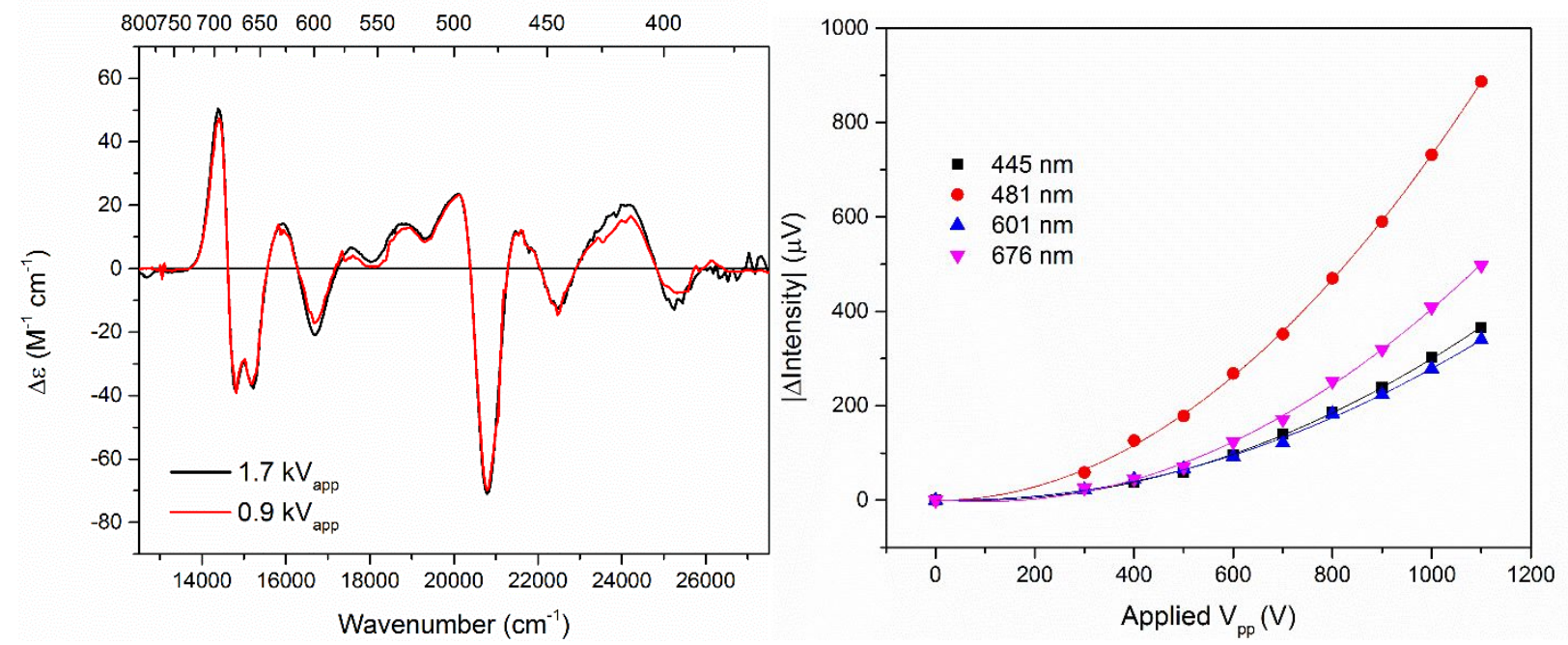

Figure S4. Electroabsorption measurements of $\left[\mathrm{Os}(\mathrm{bpy})_{3}\right]^{2+}$ at the indicated applied field strengths. (Left) Full Stark spectra scaled to an applied Field of $1 \mathrm{MV} / \mathrm{cm}$. (Right) The absolute value of the intensity of the electroabsorption feature measure at the indicated wavelength as a function of the field strength. Overlaid are quadratic fits. 


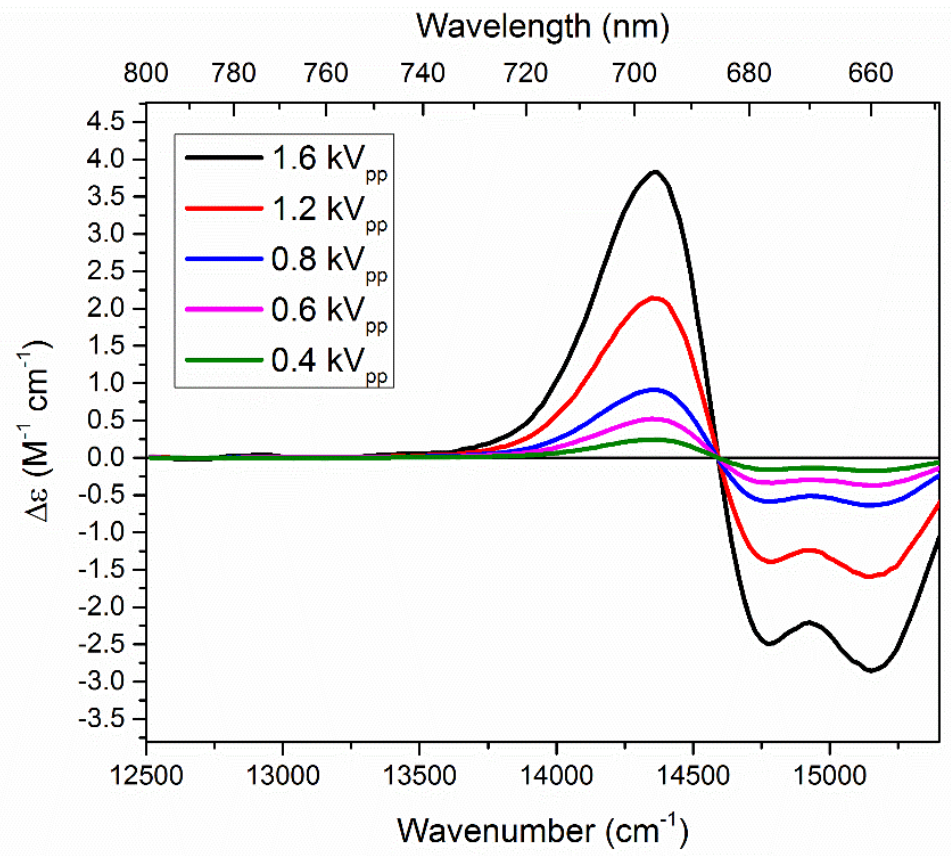

Figure S5. Stark spectra of the low energy region of $\left[\mathrm{Os}(\mathrm{bpy})_{3}\right]^{2+}$ recorded at different field strengths without normalization.

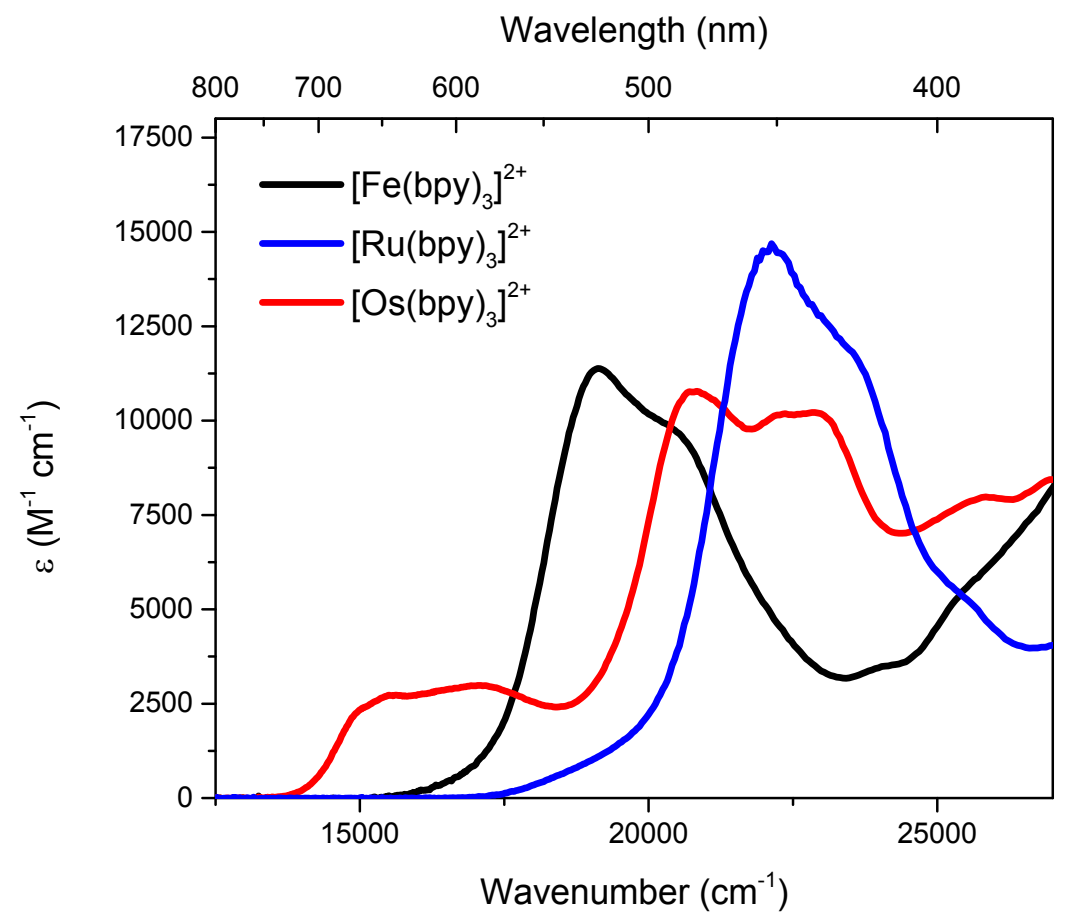

Figure S6. Room temperature UV-vis spectra of the indicated complex in butyronitrile. 
Table S1. Change in Polarizability $\operatorname{Tr}(\Delta \vec{\alpha})$ and Dipole Moment $|\Delta \vec{\mu}|$ for $\left[\mathrm{Fe}(\mathrm{bpy})_{3}\right]^{2+}$

\begin{tabular}{|c|c|c|}
\hline Wavenumber $\left(\mathbf{c m}^{-\mathbf{1}}\right)$ & $\boldsymbol{T r}(\boldsymbol{\Delta} \overrightarrow{\boldsymbol{\alpha}})\left(\AA^{\mathbf{3}} / \boldsymbol{f}_{\text {int }}{ }^{\mathbf{2}}\right)$ & $|\boldsymbol{\Delta} \vec{\mu}|\left(\boldsymbol{f}_{\text {int }} \mathrm{D}\right)$ \\
\hline $17060(\mathrm{D})$ & 1230 & 11 \\
\hline 17990 (C) & 500 & 10.3 \\
\hline 18460 & 60 & 10.3 \\
\hline 19000 (B) & 0 & 11.1 \\
\hline 20060 (A) & 530 & 10 \\
\hline 21020 & 5 & 6.8 \\
\hline
\end{tabular}

Table S2. Change in Polarizability $\operatorname{Tr}(\Delta \vec{\alpha})$ and Dipole Moment $|\Delta \vec{\mu}|$ for $\left[\operatorname{Ru}(b p y)_{3}\right]^{2+}$

\begin{tabular}{|c|c|c|}
\hline Wavenumber $\left(\mathbf{c m}^{-1}\right)$ & $\boldsymbol{T r}(\boldsymbol{\Delta} \overrightarrow{\boldsymbol{\alpha}})\left(\AA^{\mathbf{3}} / \boldsymbol{f}_{\text {int }}{ }^{\mathbf{2}}\right)$ & $|\boldsymbol{\Delta} \vec{\mu}|\left(\boldsymbol{f}_{\text {int }} \mathrm{D}\right)$ \\
\hline $17830(\mathrm{D})$ & 580 & 5.3 \\
\hline $19270(\mathrm{C})$ & 170 & 6.5 \\
\hline 20390 & 16 & 5.8 \\
\hline 20860 & 50 & 1 \\
\hline 21250 & 800 & 0.24 \\
\hline $21550(\mathrm{~B})$ & 150 & 8.3 \\
\hline $22900(\mathrm{~A})$ & 155 & 7.1 \\
\hline 24480 & 3 & 3.8 \\
\hline
\end{tabular}

Table S3. Change in Polarizability $\operatorname{Tr}(\Delta \vec{\alpha})$ and Dipole Moment $|\Delta \vec{\mu}|$ for $\left[\operatorname{Os}(b p y)_{3}\right]^{2+}$

\begin{tabular}{|c|c|c|}
\hline Wavenumber $\left(\mathrm{cm}^{-1}\right)$ & $\boldsymbol{T r}(\boldsymbol{\Delta} \overrightarrow{\boldsymbol{\alpha}})\left(\AA^{\mathbf{3}} / \boldsymbol{f}_{\text {int }}{ }^{\mathbf{2}}\right)$ & $|\boldsymbol{\Delta}|\left(\boldsymbol{f}_{\text {int }} \mathrm{D}\right)$ \\
\hline $14650(\mathrm{D})$ & 630 & 4.5 \\
\hline 15150 & 175 & 7.5 \\
\hline $16680(\mathrm{C})$ & 30 & 7.35 \\
\hline 18020 & 3.5 & 4 \\
\hline 19250 & 185 & 1.2 \\
\hline 19970 & 77 & 0.85 \\
\hline $20780(\mathrm{~B})$ & 10 & 6.6 \\
\hline 20550 & 775 & 0.55 \\
\hline $22200(\mathrm{~A})$ & 37 & 5.1 \\
\hline 24030 & 45 & 0.262 \\
\hline
\end{tabular}




\section{Electronic Structure Analysis}

For a full analysis of the electronic structure using group theory in a $D_{3}$ symmetry please refer to Kober et $a l .6$

Using the $\mathrm{MO}$ scheme presented in the main text (Scheme 1); there are four different orbital transitions: $d \pi_{A 1} \rightarrow \pi^{*}{ }_{A 2} d \pi_{E} \rightarrow \pi_{A 2}^{*} d \pi_{E} \rightarrow \pi_{E}^{*}$ and $d \pi_{E} \rightarrow \pi_{A 2}^{*}$. Following light absorption, the resulting excited state has one electron localized on a ligand orbital and five electrons in metal localized orbitals. The spin state was determined by the spin of the uncoupled electron in the metal orbitals along with the spin of the electron in the ligand centered orbital as either singlet or triplet. From the four possible orbital transitions, 6 singlet states and 18 triplet states result, Table S4.

Table S4. Tabulation of the different excited states and the Group Theory orbitals they originate from.

\begin{tabular}{|c|c|}
\hline Transition & Resulting States \\
\hline$d \pi_{E} \rightarrow \pi^{*}{ }_{A 2}$ & ${ }^{1} \mathrm{E}: 1 \mathrm{E}$ \\
\hline & ${ }^{3} \mathrm{E}: 2 \mathrm{E}, 3 \mathrm{E}, 1 \mathrm{~A}_{1}, 1 \mathrm{~A}_{2}$ \\
\hline$d \pi_{A 1} \rightarrow \pi^{*}{ }_{A 2}$ & ${ }^{1} \mathrm{~A}_{2}: 2 \mathrm{~A}_{2}$ \\
\hline & ${ }^{3} \mathrm{~A}_{2}: 2 \mathrm{~A}_{1}, 4 \mathrm{E}$ \\
\hline$d \pi_{E} \rightarrow \pi^{*}{ }_{E}$ & ${ }^{1} \mathrm{E}: 5 \mathrm{E}$ \\
\hline & ${ }^{1} \mathrm{~A}_{1}: 3 \mathrm{~A}_{1}$ \\
\hline & ${ }^{1} \mathrm{~A}_{2}: 3 \mathrm{~A}_{2}$ \\
\hline & ${ }^{3} \mathrm{E}: 6 \mathrm{E}, 7 \mathrm{E}, 4 \mathrm{~A}_{1}, 4 \mathrm{~A}_{2}$ \\
\hline & ${ }^{3} \mathrm{~A}_{1}: 5 \mathrm{~A}_{2}, 8 \mathrm{E}$ \\
\hline & ${ }^{3} \mathrm{~A}_{2}: 5 \mathrm{~A}_{1}, 9 \mathrm{E}$ \\
\hline & ${ }^{1} \mathrm{E}: 10 \mathrm{E}$ \\
\hline & ${ }^{3} \mathrm{E}: 11 \mathrm{E}, 12 \mathrm{E}, 6 \mathrm{~A}_{1}, 6 \mathrm{~A}_{2}$ \\
\hline
\end{tabular}

As the ground state has $A_{1}$ symmetry, transitions to any excited $A_{1}$ symmetric states are dipole forbidden and likely not observed. The $A_{2}$ symmetric excited states are predominantly $Z$ polarized, and as the spectrum of these species are predominantly $X Y$ polarized, ${ }^{6,8-9}$ the $A_{2}$ MLCT states are expected to be substantially weaker as the transition dipole and electron transfer do not coincide. Lastly, several of the $E$ symmetric states are nearly degenerate in energy and have not been resolved.

All of these factors combined reduce the number of states significantly. Indeed, with removal of the $A_{1}$ states, only 18 states remain. Overlap of positioning and expected weak transitions lead to defining the spectral region investigated herein as 10 transitions for $\left[\mathrm{Os}(\mathrm{bpy})_{3}\right]^{2+}, 8$ transitions for $\left[\mathrm{Ru}(\mathrm{bpy})_{3}\right]^{2+}$, and 5 transitions for $\left[\mathrm{Fe}(\mathrm{bpy})_{3}\right]^{2+}$. The fits of the UV-vis region with the individual transitions is shown. 


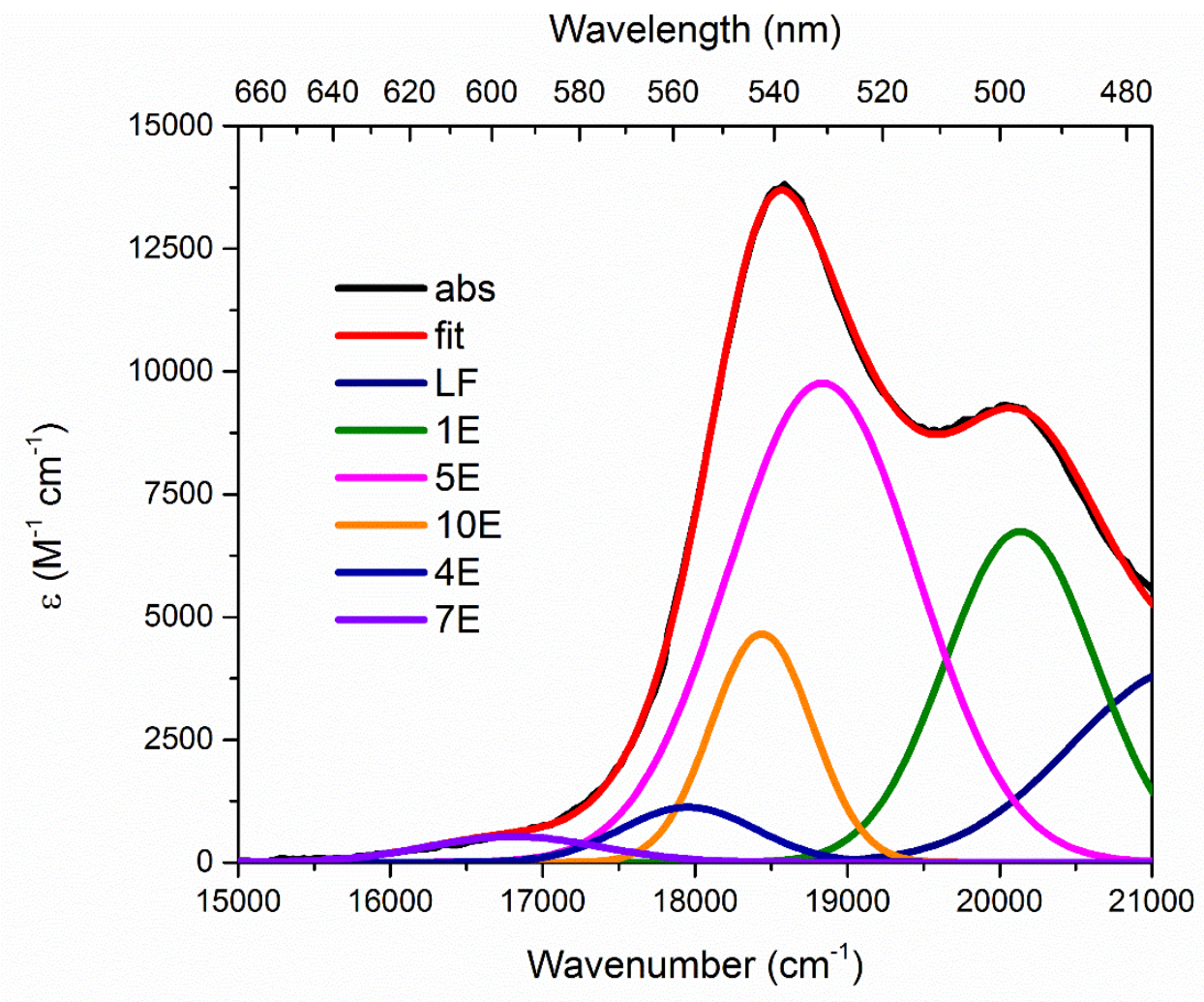

Figure S7. The 77K absorption spectrum of $\left[\mathrm{Fe}(\mathrm{bpy})_{3}\right]^{2+}$ in butyronitrile (black). Overlaid are individual transitions labelled with reference to Table $\mathrm{S} 4$ and a summation of the individual transitions (red).

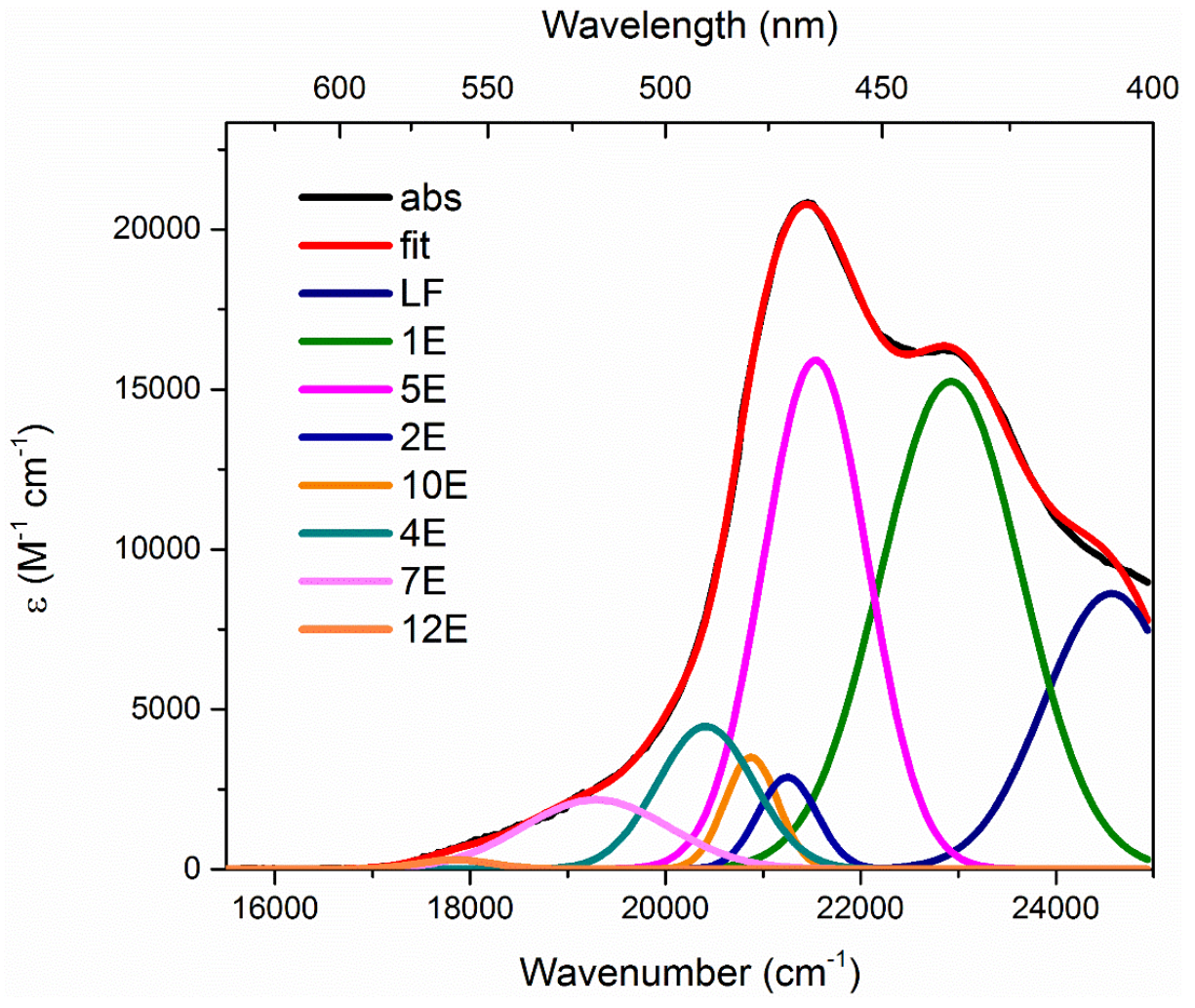


Figure S8. The 77K absorption spectrum of $\left[\mathrm{Ru}(\mathrm{bpy})_{3}\right]^{2+}$ in butyronitrile (black). Overlaid are individual transitions labelled with reference to Table $\mathrm{S} 4$ and a summation of the individual transitions (red).

Wavelength $(\mathrm{nm})$

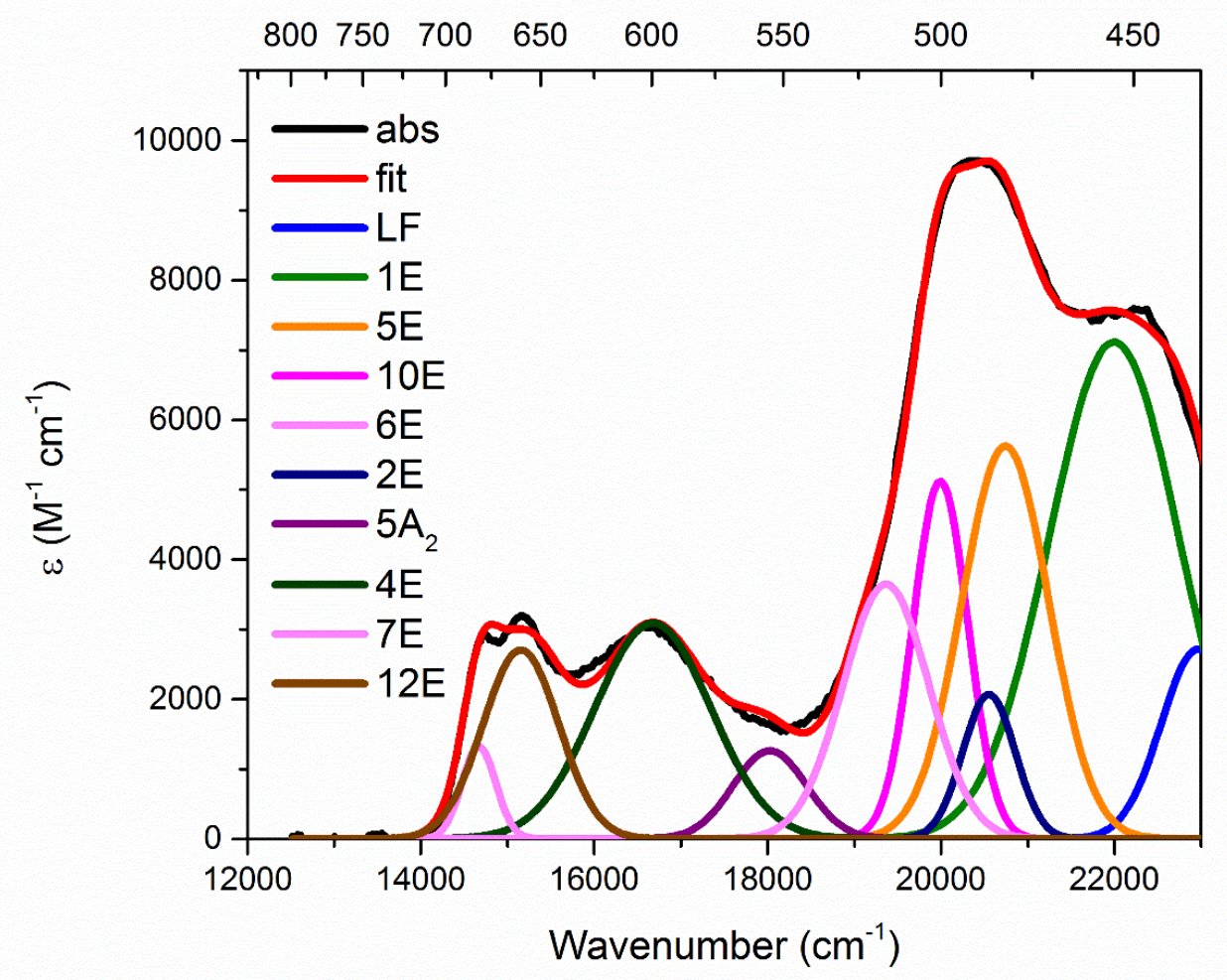

Figure S9. The 77K absorption spectrum of $\left[\mathrm{Os}(\mathrm{bpy})_{3}\right]^{2+}$ in butyronitrile (black). Overlaid are individual transitions labelled with reference to Table S4 and a summation of the individual transitions (red).

Table S5. Metal center molecular orbital coefficients in the indicated LUMO orbitals.*

\begin{tabular}{|c|c|c|c|}
\hline Orbital & Fe & Ru & Os \\
\hline $1 S$ & 0.00004 & 0.00014 & -0.00004 \\
\hline $2 S$ & -0.00002 & -0.00014 & 0.00006 \\
\hline $3 S$ & -0.00026 & 0.00013 & -0.00014 \\
\hline $4 P X$ & 0.00876 & -0.00190 & -0.00622 \\
\hline $4 P Y$ & -0.00952 & -0.01156 & 0.00532 \\
\hline $4 P Z$ & 0.00043 & -0.00031 & 0.00000 \\
\hline $5 P X$ & -0.07710 & 0.01744 & 0.06949 \\
\hline $5 P Y$ & 0.08360 & 0.09525 & -0.06001 \\
\hline $5 P Z$ & -0.00412 & 0.00100 & -0.00025 \\
\hline $6 P X$ & 0.03706 & -0.00556 & -0.01584 \\
\hline $6 P Y$ & -0.04027 & -0.03578 & 0.01372 \\
\hline $6 P Z$ & 0.00222 & -0.00081 & -0.00002 \\
\hline $7 D 0$ & 0.00004 & 0.00031 & -0.00010 \\
\hline
\end{tabular}




\begin{tabular}{|c|c|c|c|}
\hline 7D +1 & -0.09006 & -0.15197 & 0.11726 \\
\hline 7D -1 & -0.08302 & 0.02580 & 0.13703 \\
\hline 7D +2 & -0.12551 & -0.06752 & 0.19299 \\
\hline 7D -2 & 0.01776 & -0.14698 & 0.04105 \\
\hline 8D 0 & 0.00003 & 0.00015 & -0.00007 \\
\hline 8D +1 & -0.03175 & -0.05862 & 0.05945 \\
\hline 8D -1 & -0.02928 & 0.01001 & 0.06954 \\
\hline 8D +2 & -0.04109 & -0.02927 & 0.10495 \\
\hline 8D -2 & 0.00582 & -0.06423 & 0.02241 \\
\hline
\end{tabular}

* Maximum amplitude is highlighted.

References

(1) Damrauer, N. H.; Boussie, T. R.; Devenney, M.; McCusker, J. K. Effects of Intraligand Electron Delocalization, Steric Tuning, and Excited-State Vibronic Coupling on the Photophysics of ArylSubstituted Bipyridyl Complexes of Ru(II). J. Am. Chem. Soc. 1997, 119, 8253-8268.

(2) Nazeeruddin, M. K.; Zakeeruddin, S. M.; Kalyanasundaram, K. Enhanced Intensities of the Ligand-toMetal Charge-Transfer Transitions in Ruthenium(III) and Osmium(III) Complexes of Substituted Bipyridines. J. Phys. Chem. 2005, 97, 9607-9612.

(3) Maurer, A. B.; Piechota, E. J.; Meyer, G. J. Excited-State Dipole Moments of Homoleptic [Ru(Bpy')3]2+ Complexes Measured by Stark Spectroscopy. J. Phys. Chem. A 2019, 123, 8745-8754.

(4) Jalviste, E.; Ohta, N. Theoretical Foundation of Electroabsorption Spectroscopy: Self-Contained Derivation of the Basic Equations with the Direction Cosine Method and the Euler Angle Method. J. Photochem. Photobiol. C Photochem. Rev. 2007, 8, 30-46.

(5) Liptay, W. Die Lösungsmittelabhängigkeit Der Wellenzahl von Elektronenbanden Und Die ChemischPhysikalischen Grundlagen. Zeitschrift fur Naturforsch. - Sect. A J. Phys. Sci. 1965, 20, 1441-1471.

(6) Kober, E. M.; Meyer, T. J. Concerning the Absorption Spectra of the lons M(Bpy)32+ (M = Fe, Ru, Os; Bpy = 2,2'-Bipyridine). Inorg. Chem. 1982, 21, 3967-3977.

(7) Frisch MJ, et al. (2010) Gaussian 09, Revision B.01 (Gaussian, Inc., Wallingford CT).

(8) Felix, F.; Ferguson, J.; Giidel, H. U.; Ludilc, A. The Electronic Spectrum of Ru(bpy) ${ }_{3}^{2+}$. J. Am. Chem. Soc. 1980, 102, 4096-4102.

(9) Decurtins, S.; Giidel, H. U.; Ludi, A.; Felix, F.; Ferguson, J. The Electronic Spectrum of Fe(bpy $)_{3}{ }^{2+}$ and Os(bpy $)_{3}{ }^{2+}$. J. Am. Chem. Soc. 1980, 102, 4102-4106. 